\title{
Hypotensive anaesthesia and blood loss in orthognathic surgery
}

\author{
Does hypotensive anaesthesia reduce blood loss in orthognathic surgery?
}

\section{K Praveen, V Narayanan, MR Muthusekhar, MF Baig. Hypotensive anaesthesia reduces blood loss in orthognathic surgery: a clinical study. Br J Oral Maxillofacial Surg 2001; 39:138-140}

Objective This trial aimed to determine whether hypotensive anaesthesia reduces blood loss during orthognathic surgery.

Design Randomised trial.

Intervention Subjects were allocated to hypotensive (24 patients) or normotensive (29 patients) groups, assigned by sealed envelope, before undergoing standard orthognathic procedure.

Outcome measure Median blood loss was measured.

Results A significant reduction in blood loss was seen with hypotensive anaesthesia (see Table 1).

Conclusions There was pronounced reduction in blood loss during orthognathic procedures carried out under hypotensive anaesthesia.

Table 1. Median (range) blood loss under hypotensive and normotensive anaesthesia.

\begin{tabular}{lccc}
\hline \multirow{2}{*}{ Variable } & \multicolumn{3}{c}{ Median (range) blood loss $(\mathrm{ml})$} \\
\cline { 2 - 4 } & $\begin{array}{c}\text { Normotensive } \\
\text { group }(n=29)\end{array}$ & $\begin{array}{c}\text { Hypotensive } \\
\text { group }(n=24)\end{array}$ & $P$ \\
\hline Total & $350(130-1575)$ & $200(90-400)$ & 0.01 \\
$\begin{array}{l}\text { Maxillary anterior } \\
\text { osteotomy }\end{array}$ & $175(100-1190)$ & $85(40-240)$ & 0.05 \\
\hline
\end{tabular}

\section{Commentary}

Randomised trials of operative and peri-operative interventions in orthognathic surgery are rare, which makes this one particularly welcome. In terms of the principal outcome measure, operative blood loss, the principal finding is clear. The clinical (rather than the statistical) significance of this study is less clear, however. For example, median blood loss under hypotensive anaesthesia was only $150 \mathrm{ml}$ less than under normotensive anaesthesia. The authors do not state whether transfusion rates were different for the two groups, but this seems unlikely. Explanations of the maximum blood loss of $1575 \mathrm{ml}$ are not given but, interestingly, maximum blood loss under normotensive anaesthesia was less than under hypotensive anaesthesia for maxillary osteotomy. Since the literature does not provide convincing evidence of clear clinical advantage in the use of hypotensive anaesthesia, other clinically relevant outcome measures might have been considered, such as visibility reductions because of operative bleeding, accuracy of bone surgery and duration of surgery. Some measure of postoperative swelling might also have been instructive, since hypotensive anaesthesia carries with it the potential risk of bleeding once blood pressure returns to normal, postoperatively. Although it is true that hypotensive anaesthesia at this level (mean arterial pressure, 70$75 \mathrm{mmHg}$ ) carries with it few risks in fit young adults, a greater magnitude of hypotensive arterial pressure (below about $60 \mathrm{mmHg}$ ) carries higher risks in some patients.

In summary, although this study provides evidence of reduced median blood loss with hypotensive anaesthesia during orthognathic surgery, the clinical significance of this finding on its own is low. Without a demonstration of clinically more important advantages, such as reduced transfusion rates, shorter operation time and more accurate surgery, the case for routine use of hypotensive anaesthesia for orthognathic surgery - in what the authors acknowledge to be in a group of young, fit patients - has not yet been made convincingly.

\section{Practice point}

- This study provides evidence of reduced median blood loss with hypotensive anaesthesia during orthognathic surgery but the case for routine use has not yet been made convincingly.

\section{Jonathan Shepherd}

Professor of Oral and Maxillofacial Surgery, University of Wales College of Medicine, Cardiff, UK

Evidence-Based Dentistry (2004) 5, 16

doi:10.1038/sj.ebd.6400238 